\title{
ROUTE TIME ESTIMATION OF SOLID WASTE COLLECTION VEHICLES BASED ON POPULATION DENSITY
}

\author{
O. APAYDIN \\ M.T. GONULLU
}

\author{
Environmental Engineering Department \\ Faculty of Civil Engineering, Yildiz Technical University \\ 34220 Esenler, Istanbul, Turkey
}

*to whom all correspondence should be addressed: e-mail: apaydin@yildiz.edu.tr

\begin{abstract}
In this study, a model for stationary container system is presented to estimate collection time based on population density per $100 \mathrm{~m}$ road distance $\left(\mathrm{LPD}_{100}\right)$. The model also estimates travel and collection times, and time spent on waiting at stop signs and traffic lights separately for stationary collection. The main scope of the model is to determine required container number (NC), the number of container locations (NCL) and collection time with stationary solid waste collection (PTC) based on $\mathrm{LPD}_{100}$. Model parameters are based on route observation using a video camera of solid waste collection in 39 districts (having $38.6 \mathrm{sq} \mathrm{m}$ area) in Trabzon City in Turkiye. Moreover, a digitized route map of Trabzon City including many layers such as road distance, container location, road direction, traffic lights was used to simulate the model. The model was tested using data obtained from collection route in Erdogdu district in Trabzon, located in Eastern Black Sea of Turkiye. Compared to observed values form a collection route in Trabzon, the model estimated route time (RTC) within \% 2.9-4.9 of error margin.
\end{abstract}

KEYWORDS: Video-camera, solid waste collection, stationary container system, linear population density, route observation.

\section{INTRODUCTION}

Due to rapid increase in population and improvement in the standard of living, the problems of solid waste generation from anthropogenic sources have become an important concern especially in developing countries. It implies that the municipal authorities would require huge capital investments and operational strategies for collection, transportation and disposal of solid waste. In solid waste management system, collection of solid waste is the most expensive part of whole disposal process. When all the management expenditure for especially big size communities is thought, this rate will be understood clearly. For example, Kinaci et al. (2000) stated that expenditure for Istanbul having a population of over 10 million is approximately $\$ 100$ million. In addition, Apaydin and Gonullu (2008) stated that the cost for waste management is $\$ 110000$ per month for Trabzon City with a population of 215000 . The causes of high collection cost are being quite spreader in a large collection area with small amount of residential wastes and unexpected waste setting out behaviors by non-participating residences. To minimize Municipal solid waste (MSW) collection costs, it is necessary to decrease travel time of collection vehicle. In collection with trucks, the more distance is traveled the more cost arises. Collection cost is approximately $\$ 0.05$ per $\mathrm{km}$ and per ton solid waste. The main objective of this study is to develop a new method for estimating MSW collection time with stationary container based on $L P D_{100}$. According to our observations in Trabzon City distances among containers are between $35 \mathrm{~m}$ to $560 \mathrm{~m}$, but preferably around $100 \mathrm{~m}$. So, in the study linear population density per $100 \mathrm{~m}$ is used in the model. Proposed model enables estimation of the required time for solid waste collection as a function of population density in a collection area. The process associated with the solid waste management can be generally classified into generation, collection, storage, processing, transportation and disposal (Tchobanoglous et al., 1993). It is known that the most important ratio of total disposal costs of solid waste management is due to collection. It is essential to find optimized 
locations and number of containers to be placed in order to achieve the best waste collection efficiency. Our model based on linear population density approximates pick up time for stationary container collection system. The model also estimates travel time based on average vehicle velocities which changes with average distance between stops (ADBS). In next sections, a method for estimating route time for stationary container collection of MSW is presented based on linear population density. The model, simulated based on linear population density was tested using data from a case study.

\section{MATERIALS AND METHODS}

\subsection{A collection model based on linear population density}

We developed the model to determine the route time by simulating a collection vehicle traveling through different collection routes. In this study, GIS database such as road distance, container, population, traffic light layers for Trabzon City was also used effectively. Figure 1 illustrates a simulated small section to demonstrate the conceptual MSW collection model. The required input information for the model contains collection method and route characteristics. Collection method examines relationships between travel time and travel distance, or collection time and amount of MSW. Collection route characteristics include the distance between all adjacent potential stops such as residences, stop sings, traffic lights, and the average time spent at stop signs and traffic lights. The time spent at stop signs and traffic lights is a function of both vehicle and route characteristics. The model requires equations to compute travel time between each pairs of stops, collection time for MSW containers, and waiting times at stop signs and traffic lights. Data were collected for 9 different routes over 13 collection days. Using a digital camera, visual records were made in the collection vehicle cabinet to observe route variations. Distances proceeded through the route were cross checked between digitized map and vehicle tachometer. The stages of the model were explained under subsections below.

\subsubsection{Solid waste pick up time with stationary container}

The time passes from discharge of solid waste from containers to collecting of wastes is here described as "Pickup time". Pickup time (PT) includes times the processes of lifting up, discharging and lifting down of container through a semi-automatic mechanism at the back the vehicle. Container is lifted up by means of a semi-automatic loading mechanism manually with the help of a worker and it is discharged into the vehicle from the back. As soon as the waste in the container is discharged into the vehicle, container is lifted down again. Solid waste PTC is estimated based on LPD 100 . Lots of studies were done in order to determine the PTC. The number of building per road distance was determined using the present map of Trabzon city having several layers such as road distance, building numbers per road distance, household numbers per building. The number of household was determined using cadastral survey and the map of Trabzon city. The amount of solid waste per inhabitant (M) was determined based on route observations and solid waste collection database. Required container volume for solid waste generation per inhabitant $\left(V_{R P}\right)$ can be calculated as

$$
V_{R P}=\frac{M}{S W_{c}}
$$

where $M$ is solid waste generation rate ( $\mathrm{kg} /$ inhabitant.day), $S W_{c}$ is average density of solid waste in container $\left(\mathrm{kg} \mathrm{m}^{-3}\right)$; required container volume for solid waste generation per household $\left(V_{R}\right)$ is calculated using the following expression

$V_{R}=P_{R} \times V_{R P}$

where $V_{R}$ is required container volume for solid waste generation per household ( $\mathrm{m}^{3} /$ household.day); $P_{R}$ is the number of mean inhabitant per household that was estimated using TURKSTAT (2000) database and household survey (Apaydin et al., 2002). LPD 100 was determined using the present map of Trabzon city, TR SIS database and in situ observations. The number of inhabitant per container $\left(\mathrm{P}_{\mathrm{NC}}\right)$ can be estimated from

$$
P_{N C}=\frac{V_{C}}{V_{R P}}
$$

where $\mathrm{V}_{\mathrm{C}}$ is container volume $\left(\mathrm{m}^{3}\right), \mathrm{P}_{\mathrm{NC}}$ is the number of inhabitant per container (inhabitant/ 
container). The average distance between container locations is given as

$A D B C=B \times L P D_{100}^{k}$

where $A D B C$ is the average distance between container locations $(m)$, B and $k$ are empirical constants estimated based on $\mathrm{V}_{\mathrm{C}}$. $\mathrm{B}$ and $\mathrm{k}$ are given in Table 1.

Table 1. The values of $B$ and $\mathrm{k}$ based on the volume of the container

\begin{tabular}{cccc}
\hline $\begin{array}{c}\text { Volume of container, } \mathbf{V}_{\mathbf{C}} \\
\left(\mathbf{m}^{3}\right)\end{array}$ & $\mathbf{B}$ & $\mathbf{k}$ & $\mathbf{R}^{\mathbf{2}}$ \\
\hline 0.3 & 11623 & -1.0021 & 0.99 \\
\hline 0.4 & 15876 & -1.0065 & 0.99 \\
\hline 0.8 & 30566 & -0.999 & 1 \\
\hline 0.9 & 34372 & -0.9989 & 0.99 \\
\hline $\mathrm{B}=37549 \times \mathrm{V}_{\mathrm{C}}+579.94$ & & & \\
$\mathrm{k}=-0.2683 \times \mathrm{V}_{\mathrm{C}}^{3}+0.528 \times \mathrm{V}_{\mathrm{C}}^{2}-0.3143 \times \mathrm{V}_{\mathrm{C}}-0.9481$ & &
\end{tabular}

NCL can be described as a ratio of route distance with container (RDC) over ADBC.

$N C L=\frac{R D C}{A D B C}$

In the equation 5, units for $\mathrm{ADBC}$ and $\mathrm{RDC}$ are in $\mathrm{m}, \mathrm{NCL}$ is unitless. The container number for a route can be obtained from

$N C=\frac{p}{P_{N C}}$

where $\mathrm{NC}$ is the number of container per route (container number/route), $\mathrm{p}$ is population per a route, $\mathrm{P}_{\mathrm{NC}}$ is the number of inhabitant per container. The average number of container located in any NCL can be given as

$A N C=\frac{N C}{N C L}$

where ANC is the average number of containers located in a NCL. An equation to estimation PTC was derived based on NCL and the average number of container (ANC) located in any NCL. PTC is presented as

$P T C=N C L \times[a+b \times(A N C)]$

where PTC is solid waste pick up time with container (s), PTC was tested for NCL=1 in residential neighborhoods in Trabzon City. (If ANC were 0 , PTC would be $5.1 \mathrm{~s}$; if ANC were 6 , PTC would be $241.68 \mathrm{~s}$; where $a=5.1 \mathrm{~s}$ and $b=39.43 \mathrm{~s} /$ container). A plot of collection time versus the number of container is presented in Figure 1. Small dots represent the raw data. The plot indicates a line fits to the means, represented by large dots. The high $\mathrm{R}^{2}$ value of 0.99 indicated a good correlation.

\subsubsection{Vehicle travel equation, time for stop sign and traffic light}

A model presented in this paper is capable of estimating route time based on population density. The model estimates travel time, collection time (total pick up time with stationary container collection), and time spend waiting at stop sings and traffic lights. Model parameters are based on observation of MSW collection process. To develop a travel equation, average vehicle speeds between containers were calculated using each run's travel time and travel distance. Average vehicle speeds between containers were plotted against the distance between each pair of containers. It is reasonable to assume that the collection vehicle will attain a higher average speed on longer runs, but that a lower average speed on shorter runs. 


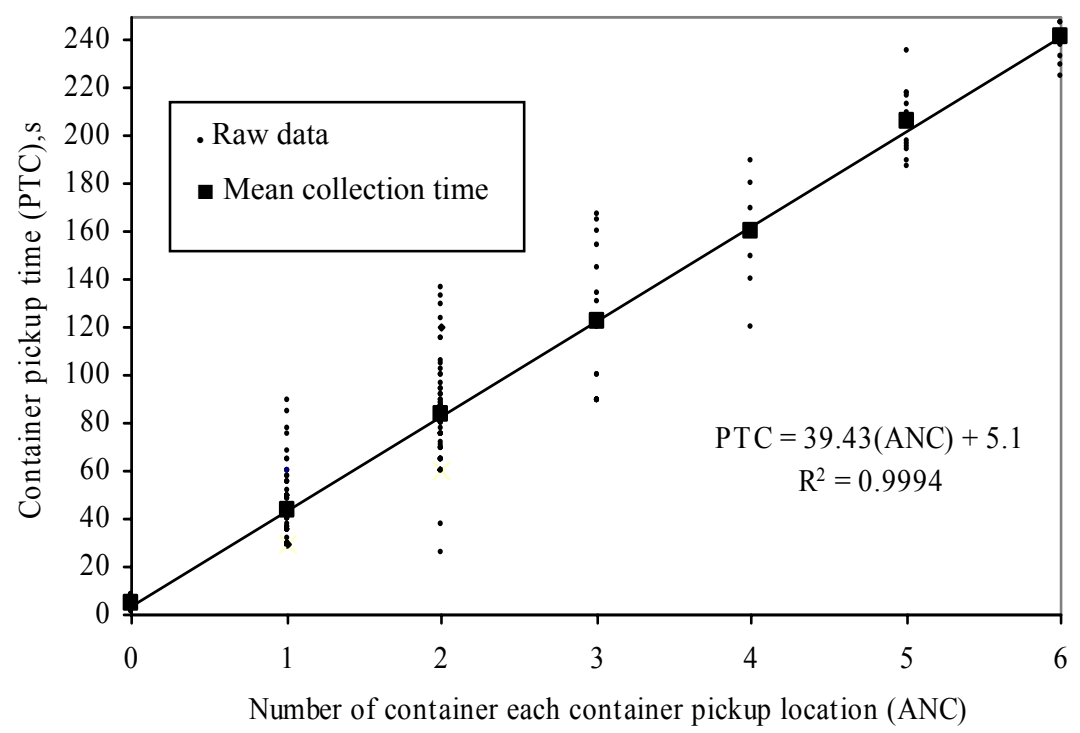

Figure 2. Container pick up time versus number of container existing per location

Using recorded data in the study area, the relationship between $A D B S$ and $V_{A V}$ can be given as $V_{A V}=5.799 \times \operatorname{Ln}(A D B S)-10.787$

where $V_{A V}$ is average speed of collection vehicle $\left(\mathrm{km} \mathrm{h}^{-1}\right)$, ADBS is average distance between stops (m) and can be presented as

$$
A D B S=\frac{R D C}{\left(N C L+n_{t l}+n_{s s}+1\right)}
$$

where $R D C$ is total collection route distance $(\mathrm{m}), N C L$ is the number of container pickup location per collection route, $n_{t l}$ is the number of traffic light per route, $n_{s s}$ the number of traffic rush per route.

The travel time equation for entire collection route can be given as

$T T C=\frac{f \times R D C}{V_{A V}}$

where TTC is total travel time of vehicle (s), $f$ is conversion factor (the value of $f$ is 3.6 in Metric units).

\subsubsection{Time for stop sign and traffic light}

The equation for computing wait time is based on the means of waiting times measured during one collection run. In a study performed by Everett and Shahi (1996), the measured means are determined to be $7.1 \mathrm{~s}$ at stop signs and $11.9 \mathrm{~s}$ at traffic lights for curbside collection of yard waste. In this study, the measured means for Trabzon City are $15 \mathrm{~s}$ at stop signs and $9.5 \mathrm{~s}$ at traffic lights. This is a fact that the processes of solid waste collection and transportation may be very complicated in residential areas because there are people whose living conditions and possibilities are quite different from each other. The results are different from each other. Time for traffic lights is

$T_{t l}=t_{t l} \times n_{t l}$

where $T_{t l}$ is waiting time for all traffic lights $(\mathrm{s}), t_{t \mid}$ is average waiting time per traffic light; $n_{t l}$ is number of traffic light per route. Time for stop signs is

$T_{s s}=t_{s s} \times n_{s s}$

where $T_{s s}$ is waiting time for stops (s), $t_{s s}$ is average waiting time due to stop signs, $n_{s s}$ is number of stop signs per route. 


\subsubsection{Estimation and verification of route time for stationary collection}

The model is capable of estimating total route time for solid waste collection with container from residential area. The equation can be given as

$$
R T C=T T C+P T C+T_{t l}+T_{s s}
$$

where RTC is total route time of vehicle on a collection route (s); and rearranging the equation (14) the final equation can be presented as

$$
R T C=\frac{f \times R D C}{5.799 \times \operatorname{Ln}(A D B S)-10.787}+N C L \times[a+b \times(A N C)]+t_{t l} \times n_{t l}+t_{s s} \times n_{s s}
$$

A case study was performed to verify the RTC for a route in Trabzon City. Trabzon is located in Eastern Black Sea Region of Turkey. The population of Trabzon city was 183000 according to TURKSTAT (2000). The population of the year 2005 of Trabzon City was also 215000 . Solid wastes are collected by stationary container using over 12 compacted trucks. The solid wastes collected with the trucks were being hauled to disposal area located in Black Sea side before the year of 2008. After that, collected MSW is hauled at transfer station and transported to Sanitary landfill founded in 2008. Sanitary landfill is located at the east of Trabzon city. Distance from Trabzon City to the sanitary landfill is $43 \mathrm{~km}$. The amount of solid waste collected was over 150 ton per day. Solid waste collection was done as 2 shifts. The case study for verifying of RTC was performed the morning shift using the truck with $15 \mathrm{~m}^{3}$. The track with compact machinery traveled to pick up the stationary container. NCL was 103 the route. NC was changing from 1 to 6 per NCL. RDC was $6895 \mathrm{~m}$. Case study was done over 6 times at the same route. Route characteristics for the stationary container system are given in Table 2.

Table 2. Route characteristics based on population per $100 \mathrm{~m}$ road distance $\left(\mathrm{LPD}_{100}\right)$

\begin{tabular}{|c|c|}
\hline Model parameters & Values \\
\hline Average distance between stops, $A D B S$ & $54.9 \mathrm{~m}$ \\
\hline Total travel distance per route, $R D C$ & $6895 \mathrm{~m}$ \\
\hline Average number of container per container location, $A N C$ & 1.14 \\
\hline Average velocity of collection vehicle, $V_{A V}$ & $13.2 \mathrm{~km} \mathrm{~h}^{-1}$ \\
\hline Empirical constant, a & $5.1 \mathrm{~s}$ \\
\hline Empirical constant, $b$ & $39.4 \mathrm{~s} /$ container \\
\hline Average waiting time per traffic light, $t_{t \mid}$ & $9.5 \mathrm{~s}$ \\
\hline Number of traffic light per route, $n_{t l}$ & 4 \\
\hline Average waiting time per stop sign, $t_{s s}$ & $15 \mathrm{~s}$ \\
\hline Number of stop sign per route, $n_{s s}$ & 3 \\
\hline Number of container per route, $N C$ & 117.4 \\
\hline Number of people living route, $p$ & 13546 \\
\hline Number of container location per route, $N C L$ & 103 \\
\hline Solid waste generation per inhabitant per day, $M$ & $0.65 \mathrm{~kg} /$ inhabitant.day \\
\hline Average density of solid waste in container, $S W_{c}$ & $250 \mathrm{~kg} \mathrm{~m}^{-3}$ \\
\hline The volume of Solid waste generation per household, $V_{R}$ & $0.0107 \mathrm{~m}^{3} /$ household.day \\
\hline The volume of Solid waste generation per day, $V_{R P}$ & $0.0026 \mathrm{~m}^{3} /$ inhabitant.day \\
\hline Container capacity, $V_{C}$ & $0.3 \mathrm{~m}^{3}$ \\
\hline Number of inhabitant per container, $P_{N C}$ & 115 inhabitant \\
\hline Number of inhabitant per $100 \mathrm{~m}$ route, $L P D_{100}$ & 197 inhabitant/100m \\
\hline
\end{tabular}
for the stationary container system

Model was performed for six collection days at a different collection route (in Erdogdu District) in Trabzon City in Turkey. The model estimated route time is $2.9-4.9 \%$ higher than observed values (Table 3). The model can be used by solid waste managers to examine a wide range of collection alternatives for a specific municipality, without the time and expense of simulation modeling labor requirement. In addition, the model could be used to determine solid waste collection requirements at new residential areas. 
Table 3. Comparison of predicted and observed route times

\begin{tabular}{cccc}
\hline $\begin{array}{c}\text { Collection } \\
\text { event }\end{array}$ & $\begin{array}{c}\text { Predicted } \\
\text { Time } \\
\text { (s) }\end{array}$ & $\begin{array}{c}\text { Observed } \\
\text { Time } \\
(\mathbf{s})\end{array}$ & Percent error \\
\hline 1 & 5245 & 5092 & 3.0 \\
\hline 2 & 5033 & 4832 & 4.2 \\
\hline 3 & 5641 & 5437 & 3.8 \\
\hline 4 & 4523 & 4312 & 4.9 \\
\hline 5 & 5812 & 5636 & 3.1 \\
\hline 6 & 5341 & 5192 & 2.9 \\
\hline
\end{tabular}

\subsubsection{THE SIMULATION OF MODEL PARAMETERS BASED ON LPD 100}

The scope of the study is to estimate PTC based on LDP 100 . Changes in values of some parameters ( $p$, ADBC, PTC, NCL) were examined and given in Table 4 based on LDP ${ }_{100}$. According to Table 4, the number of vehicles (column 4) increases with an increase in LDP $_{100}$. Number of vehicle can be estimated from:

$N V=\frac{N C \times V_{C}}{V_{V} \times r}$

where NV is the number of vehicle, $V_{V}$ is the volume of vehicle, and $r$ is compaction factor $(r=2)$.

Table 4. Change on route characteristics based on population per $100 \mathrm{~m}$ route distance $\left(\mathrm{LPD}_{100}\right)$ for the stationary container system

\begin{tabular}{|c|c|c|c|c|c|c|c|c|c|c|c|}
\hline 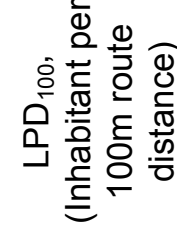 & 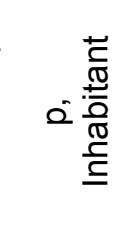 & $\begin{array}{l}\mathscr{\rho}^{\circ} \varepsilon \\
\text { 安 }\end{array}$ & $\begin{array}{l}0^{\circ} \\
\text { 蓆 } \varepsilon\end{array}$ & $\frac{\dot{U}}{z} \varepsilon$ & u & $\stackrel{U^{\circ}}{F} \infty$ & $\dot{b}_{0}^{0} \infty$ & $\frac{j}{\not} \infty$ & 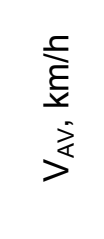 & 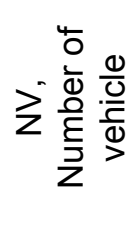 & 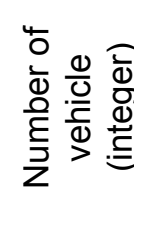 \\
\hline (1) & (2) & (3) & (4) & (5) & (6) & $(7)$ & $(8)$ & (9) & (10) & (11) & (12) \\
\hline 100 & 6000 & 218.1 & 307.6 & 20 & 19.5 & 1622.4 & 886.4 & 2591.7 & 20.4 & 0.5 & 1 \\
\hline 120 & 7200 & 191.1 & 256.4 & 23 & 23.4 & 1663.7 & 1064 & 2810.5 & 19.7 & 0.6 & 1 \\
\hline 200 & 12000 & 128.0 & 153.9 & 39 & 39.0 & 1812.3 & 1774 & 3668.9 & 17.3 & 1 & 1 \\
\hline 220 & 13200 & 118.1 & 139.9 & 43 & 42.9 & 1846.5 & 1951 & 3880.7 & 16.8 & 1.1 & 2 \\
\hline 300 & 18000 & 90.3 & 102.7 & 58 & 58.5 & 1976.6 & 2661 & 4721.0 & 15.3 & 1.6 & 2 \\
\hline 320 & 19200 & 85.2 & 96.2 & 62 & 62.4 & 2007.9 & 2839 & 4929.8 & 14.9 & 1.7 & 2 \\
\hline 400 & 24000 & 69.7 & 77 & 78 & 78.0 & 2129.5 & 3549 & 5761.8 & 13.8 & 2.1 & 3 \\
\hline 420 & 25200 & 66.6 & 73.4 & 82 & 81.9 & 2159.3 & 3727 & 5969.2 & 13.5 & 2.2 & 3 \\
\hline 500 & 30000 & 56.7 & 61.6 & 98 & 97.5 & 2276.9 & 4437 & 6797.3 & 12.6 & 2.6 & 3 \\
\hline
\end{tabular}




\section{RESULTS AND DISCUSSION}

Solid waste collection process can be carried out by collecting the wastes accumulated in containers of constant volumes. Model parameters are shown in Table 2 for a different collection route performed on different times. When unit solid waste amount on a route distance and number of people per $100 \mathrm{~m}$ unit road are known, the other parameters can be determined using the model. NCL, NC, ANC, ADBC, $V_{A V}$, PTC, TTC and RTC can be determined with this model. If LDP $_{100}$ is between 100 and 500 value of parameters used in the model are demonstrated in Table 4 . When $\mathrm{LDP}_{100}$ is known, change of variations in model parameters can be analyzed. If an increase in LDP $_{100}$, will increases NC, solid waste PTC, TTC, RTC and NV. But ADBS and $V_{A V}$ decrease. This model can be suitable for any working area where numbers of container points are determined. Knowing the number of container points, the numbers of containers that must be placed, solid waste pick up time, vehicle's travel time, duration of waiting at traffic lights, duration of waiting due to traffic density, vehicle's average speed and route durations of vehicles can be approximated with this model. The model can be implemented with the exemplification and analysis of basic parameters that are used in determining the needs of solid waste collection process. Data illustrated in Figure 1 is acquired from digital camera records on November 2004. From Figure 1 the line can be fit to the means with a high $R^{2}$ value of 0.99 . Solid waste pick up time is estimated based on the number of containers located in anywhere on the route where stationary container collection is performed. Costs of solid waste collection process constitute the most important part of solid waste collection costs. Realization of this process with the lowest cost is very important especially in developing countries. Collection of solid wastes is performed with containers or from curbsides. In some places processes of collection both containers and curbsides in the same route are carried out at the same time. In this study, it was investigated how long it would take to load containers in different places by means of back-load type vehicles with automatic squeezing mechanisms. Container pick up time was estimated based on number of containers (Figure 1) obtained from observations on November 2004. In any collection route, solid waste pick up time for the process of collection with container can be estimated with this model using number of container points and average number of containers. For waste collection from curbsides, collection vehicles visit nearly all the streets and avenues to collect wastes disposed by dwellings. In the collection process with containers the distance of routes that collection vehicles have to visit is remarkably shorter in comparison to collection from curbsides as families leave their wastes in containers which are placed at certain points on streets and avenues after walking for 4-5 minutes. In a few studies conducted in Trabzon, it was determined that for collections much more time is needed for the waste collection from curbsides in comparison to the process of collecting with containers (Apaydin, 2004; 2005; Apaydin and Gonullu, 2007). Discharge of containers into vehicle takes less time in comparison to process of collecting from curbsides in solid waste collection process. Based on all these observations and investigations, it is thought that process of collecting with containers is more suitable than curbside collection in terms of cost and times per unit MSW. In the planning of solid waste collection work for any new settlement, following parameters can be estimated with the model stated in this study for collection with containers if population per $100 \mathrm{~m}$ route distance is known: Number of container points necessary for route based on container volume, Number of containers necessary for route based on container volume, Collection time with containers for solid waste collection process, Travel time for solid waste collection process, Route time for solid waste collection process. Total pick up time can be estimated based on population inhabiting through the route for two solid waste collection types. The number of container could be computed based on population per $100 \mathrm{~m}$ road distance. The model was performed in the study area for inhabitant between 100 and 361 per $100 \mathrm{~m}$ road distance in September 2007. This model can be applied to other settlement areas, where container points are previously determined. This model can be also used to determine container locations for other places as long as $L^{2} D_{100}$ is known. The practice was tested for 6 days in a 13-day period of time by means of $15 \mathrm{~m}^{3}$ volume back load vehicles with compact mechanism on a route of $6895 \mathrm{~m}$ length in Erdogdu quarter in a route different from the routes followed up for model verification in September 2007. It was determined that there was \%2.9-4.9 error when the available data was compared with model data. In the future research, the equation parameters should be determined for other collection systems, such as compostables, recyclable, or yard wastes. A database of parameters should be developed using geographical information system (GIS). GIS database can be used in the design and comparison of collection programs. 


\section{CONCLUSIONS}

The topic of solid waste collection merits special consideration due to the fact that it is the most expensive part of the entire solid waste management system. Hence, in this study, a model for stationary container system is presented to estimate the collection time based on the population density per $100 \mathrm{~m}$ road distance $\left(\mathrm{LPD}_{100}\right)$. This model can be suitable for any working area where numbers of container points are determined. If It is known $L P D_{100}$, the number of container points, solid waste pick up time, vehicle's travel time, duration of waiting at traffic lights, duration of waiting due to traffic density, vehicle's average speed and route durations of vehicles can be estimated with this model. The model can be implemented to determine values of basic parameters of solid waste collection process. To plan the solid waste collection process in any new settlement, the parameters can be estimated to aid the model. In the future research, the equation parameters can be determined for other collection systems, such as compostables, recyclable, or yard wastes.

\section{ACKNOWLEDGMENTS}

The authors thank the Municipality of Trabzon and the Municipality of Besiktas for assistance in the case studies. This research was supported by Yildiz Technical University Scientific Projects Coordination Department (Project Number: 25/05/02.02).

\section{REFERENCES}

Apaydin O. (2004) Geographical Information System (GIS) Supported Optimization of Solid Waste Management Alternatives in Trabzon City, PhD thesis, Yildiz Technical University, Institute of Science, Environmental Engineering, Istanbul, Turkey.

Apaydin O. (2005) A GIS Supported Optimization Application of Solid Waste Collection System in Trabzon City, Ekoloji, 54, 1-6.

Apaydin O., Gonullu M.T. (2007) Route Optimization for Solid Waste Collection: Trabzon (Turkey) Case Study, Global NEST J., 9, 6-11.

Apaydin O., Gonullu M.T. (2008) Emission control with route optimization in solid waste collection process: A case study, Sadhana, 33(2), 71-82.

Apaydin O., Kalender A., Gonullu M.T. (2002) Assessment of Sociological Aspect of Separate Household Solid Waste Collection in Trabzon (Turkey). ISWA 2002 World Environmental Congress and Exhibition, Istanbul, Turkey, pp 2955-2960.

Everett J.W. and Shahi S. (1996) Curbside Collection of Yard Waste: II. Simulation and Application, ASCE Journal of Environmental Engineering, 122, 115-121.

Kinaci C., Görgün E., Arslan M., Armağan B. (2000) Private Sector Participation in Municipal Solid Waset Services-A Case Study for Kadıköy of Istanbul in Türkiye. Wastecon 2000, Biennial Conference and Exhibition on Integrated Waste Management inThe Millennium, Sommerset west near Cape Town, South Africa.

Tchobanoglous G., Theisen H., Vigil S.A. (1993) Integrated Solid Waste Management: Engineering Principles and Management Issues. McGraw-Hill, New York, USA.

TURKSTAT (Republic of Turkey, Prime Ministry Turkish Statistical Institute) (2006) Census 2000, Ankara, Turkey. 